\title{
The Use of Internet for Seeking Health Information Among Narh-Bita College Students: A Cross-sectional Study
}

\author{
Zakaria Abukari \\ Narh-Bita College Library, Narh-Bita College, Tema, Ghana \\ Email address: \\ zakariaabukari570@yahoo.com \\ To cite this article: \\ Zakaria Abukari. The Use of Internet for Seeking Health Information Among Narh-Bita College Students: A Cross-sectional Study. \\ American Journal of Information Science and Technology. Vol. 5, No. 2, 2021, pp. 19-24. doi: 10.11648/j.ajist.20210502.11
}

Received: December 4, 2020; Accepted: December 11, 2020; Published: May 8, 2021

\begin{abstract}
The Internet provides information on a variety of subjects including health-related information. Access to Internet health information could potentially promote healthy adolescents' lifestyles. Consequently, this may reduce the number of common illness among the youth and thereby reducing the overall cases at health centers. This study was carried out to examine the use of Internet for seeking health information among Narh-Bita College students, Tema, Ghana. The study was a quantitative cross-sectional survey with a convenience sampling method. The study covered one hundred and sixty-one (161) students. The results revealed that the students were active users of the Internet and majority of them were using the Internet for seeking health information. The findings of the study also showed that the surveyed students considered obtained Internet health information useful. In addition, the participants confirmed that obtaining Internet health information had improved the way they took care of themselves. The results further revealed that health information obtained from the Internet was having influence on the students with regards to their interactions with health care providers and their medical decision-making. The study therefore concludes that students of higher education of learning are active Internet users as well as high consumers of Internet health information despite the fact that advanced searching skills among the sampled students seemed problematic. Hence, the study recommends that electronic searching training sessions should be organized on regular basis for the students in addiction to making e-health information easily accessible to all.
\end{abstract}

Keywords: Internet Use, Health Information, On-line Health Information, College Students, Narh-Bita College

\section{Introduction}

In today's world, the Internet has become a significant and integral part of people's lives, especially among young people. It is used at homes, in the offices, at school campuses, in Internet cafes, and many other locations. It serves several purposes including for communication, education, entertainment, finance, and work-related research purposes.

The use of the Internet among the general population has seen a rapid growth worldwide over the past couple of years In the United States, $81 \%$ of adult Americans in 2019 were reported to have gone on-line on daily basis and roughly three in every ten Americans and $48 \%$ of young adults aged between 18 and 29 years old were found to be almost constantly on-line [1]. Today, many young people are technological savvy because they have been privileged to grow up in a technological rich world and are therefore recognized as active users of the Internet [2]. They have abundance access to Internet enabled devices such as computers, tablets, and smart phones. They spend long hours of their time on-line for different purposes including chatting, searching for information, and ex cetera. Higher Internet user rates are a common phenomenon in most developed world and the developing world. For example, a study carried out in most European Universities by [3] reported that $87.6 \%$ of students surveyed were using the Internet several times a day, $98.5 \%$ of the students were found to own a computer and a significant majority were further reported to be accessing the Internet at home. Similarly, in Ghana, research has shown that $48 \%$ of Ghanaians have been using the Internet frequently over the past five years [4] and $80 \%$ of young people in Ghana own a mobile phone or tablet with Internet access [5] and a further $40 \%$ of young Ghanaians have Internet access at their homes [6].

Undoubtedly, the Internet has emerged as a prominent 
and popular source for health information for this current generation of young people [7]. It contains volumes of health information which is quality, relevant, timely, and evidence-based. Health information includes information on healthy living, preventing and managing diseases, sexual health, making decisions about health products and making decisions related to health and health care [8]. It is convenient to access health information on-line and patients or clients anonymity is guaranteed. Also, access to Internet health information reduces the stigmatization and embarrassment associated with seeking sensitive health information. In Australia, young people report that they appreciate on-line interactions concerning mental health because of its anonymity, accessibility and mode of delivery [9]. According to Wang et al. using the Internet to gather health information is considered as a predictive of a healthy lifestyle [10]. Furthermore, with the convenience and ease of access to on-line health information, a lot of patients and individuals are now health conscious; they are now able to make informed decisions regarding their health [11-17]. Several previous studies have shown that apart from the high consumption of on-line health information among young adolescents, Internet health information has made a tremendous change in the pattern of young people healthy behaviors $[2,14,16,18-20]$. In some developing countries, there are limited health facilities and medical resources, delays in accessing health care couple with a high prevalence of health-related problems among the youth [21]. This poses a serious challenge, given that some research suggests that the current young adult population demonstrate difficulties in accessing mainstream health services [2], as a result of these problems, the Internet has become a good option for meeting the health care and health information needs of the youth [22].

However, concerns have been raised about the quality, reliability and usefulness of Internet health information. These concerns are largely due to the significant amount of health information and junk information on the Internet [21] and the worry is that students who lack the necessary searching skills may not be able to search and obtain relevant on-line health information. Nonetheless, the Internet offers huge volumes of quality, current and reliable health information. Besides, several previous studies have found Internet health information to be quality, useful, and reliable [19-21, 23].

There are few studies on college students' Internet utilization for health information in Ghana and as such, no similar study has been conducted at the Narh-Bita College. Additionally, the few studies that have been carried out on this subject have focused on non-science or non-medical students use of the Internet for health information, thus empirical data on the subject among health-based or science students is largely lacking. Hence, this present study seeks to complement other studies and possibly identify and fill gaps in the use of Internet for health information among the NarhBita college students.

\section{Methodology}

The study employed a descriptive cross-sectional survey design. The population of the study covered one hundred and sixty-one (161) students who had returned back to the College campus for their supplementary lectures after the relaxing of Covid-19 restrictions. A convenience sample procedure was therefore used for the study as the researcher contacted the available students to serve as respondents. These students included $3^{\text {rd }}, 4^{\text {th }}$ year students of BSc Physician Assistantship, $2^{\text {nd }}, 3^{\text {rd }}$ year students of Registered General Nursing, and $2^{\text {nd }}$ year students of Registered Nurse Assistant Clinicals. A questionnaire was used as an instrument for data collection. The questionnaire design was based on themes that emerged from the extensive literature review and the objectives of the study. The 20-item questionnaire was designed using Google Forms and each class representative was contacted to post the survey link on the class' Whats App platform for the students to response to the questionnaire. Participation was voluntary and their consent sought. The students were further assured of their anonymity and confidentiality before they completed the questionnaire. For content validity and readability of the questionnaire, it was first pre-tested on ten (10) of the College students who were selected at random and the appropriate corrections effected. These students were excluded from the main study. The questionnaire explored the demographic information of the respondents, their Internet use, and their use of the Internet for health information. All questions were closed-ended. Data collection took place between the months of September to October 2020. All data collected were analyzed using frequency counts and percentages. After a three weeks period, of the one hundred and sixty-one (161) students who had access to the survey link, one hundred and five (105) students completed and submitted their responses, giving a response rate of $65 \%$.

\section{Results and Analysis}

A total of one hundred and sixty-one (161) students were sent the questionnaire via a Google Form link and one hundred and five (105) responses were received giving a response rate of $65 \%$. Female participants dominated the study with $79 \%$, followed by $21 \%$ males. The majority of the respondents $(61 \%)$ were young $(<26$ years of age). In terms of programme of study of the participants, Registered General Assistant Clinicals (RNAC) students were the highest represented (51.4\%), followed by Physician Assistantship students (26.7\%), and Registered Nursing students $(21.9 \%)$. Also, nearly $60 \%$ of the participated students were in their second year. Table 1 shows the demographic characteristics of respondents.

\subsection{Internet Use}

This section of the study dealt with respondents' Internet use considering fact that the Internet has become very 
common and available everywhere. Today's students have abundance access to Internet enabled gadgets such as computers, tablets, smart phones etc. Therefore the researcher sought to know their Internet use by asking the following questions as shown in Table 2 .

Table 1. Demographic Information of Participants.

\begin{tabular}{lll}
\hline Age Groups & Frequency & Percentage (\%) \\
\hline $16-20$ & 10 & 9.5 \\
$21-25$ & 64 & 61 \\
$26-30$ & 21 & 20 \\
31 and above & 10 & 9.5 \\
Gender & & \\
Male & 22 & 21 \\
Female & 83 & 79 \\
Programme of study & & \\
Physician Assistantship (Bsc) & 28 & 26.7 \\
Registered General Nursing (Diploma) & 23 & 21.9 \\
Registered General Nurse Clinicals & 54 & 51.4 \\
(Cert) & & \\
Level or Year of study & & \\
Second Year (Level 200) & 63 & 59.6 \\
Third Year (Level 300) & 25 & 24 \\
Fourth Year (Level 400) & 17 & 16.3 \\
\hline
\end{tabular}

Table 2. Respondents Internet Usage.

\begin{tabular}{lll}
\hline Questions & Frequency & Percentages (\%) \\
\hline Internet use & & \\
Yes & 93 & 98 \\
No & 2 & 2 \\
Frequency of Internet use & & \\
Daily & 98 & 93.3 \\
Weekly & 1 & 1 \\
Once a while & 4 & 4 \\
Never & 2 & 2 \\
Internet use experience & & \\
2-3 years & 11 & 10 \\
4-5 years & 20 & 19 \\
6-7 years & 24 & 23 \\
8 years plus & 47 & 45 \\
Ownership of devices & & \\
Desktop/Laptop & 32 & 31.1 \\
Tablet & 18 & 17.5 \\
Smart Phone & 94 & 91.3 \\
\hline
\end{tabular}

Table 2 shows that almost all the respondents (98\%) were using the Internet and the frequency of Internet use showed that an overwhelming majority $(93 \%)$ of the students were using it daily. In addiction, when the experience of Internet use among the respondents was sought, the results showed that a significant majority $(87 \%)$ of the respondents reported being very experienced. In terms of device ownership (here respondents were asked to choose as many as applicable), the results showed that about one-third (32\%) of the students owned more than two devices, while overwhelming majority (91.3\%) owned smart phones, 31.1\% owned desktop or laptop computer, and only $17.5 \%$ owned a tablet.

\subsection{Use of Internet for Seeking Health Information}

The use of the Internet for health information has become a common phenomenon especially among the current generation of young people. The Internet contains significant amount of health information. Internet health information could be accessed at a convenient and at a minimum effort. Consequently, these people are becoming better informed of their medical conditions and are demanding improved clinical services. The purpose of this section was therefore to examine respondents' Internet use for health information by asking the following questions and the responses have been presented in the table below.

Table 3. Respondents Internet use for health Information.

\begin{tabular}{|c|c|c|}
\hline Questions & Frequency & Percentage (\%) \\
\hline \multicolumn{3}{|l|}{ Internet use for health Information } \\
\hline Yes & 102 & 97 \\
\hline No & 1 & 1 \\
\hline \multicolumn{3}{|c|}{ Frequency of searching health information on-line } \\
\hline Always & 75 & 71 \\
\hline Once a while & 27 & 26 \\
\hline Never & 1 & 1 \\
\hline \multicolumn{3}{|c|}{ Kind or type of health information that prompts searching } \\
\hline $\begin{array}{l}\text { Causes or symptoms of health } \\
\text { condition or disease }\end{array}$ & 88 & 84.6 \\
\hline $\begin{array}{l}\text { Management or treatment of disease or } \\
\text { health condition }\end{array}$ & 79 & 76 \\
\hline Prescription or drug information & 66 & 63.5 \\
\hline Nutrition or exercise information & 69 & 66.3 \\
\hline \multicolumn{3}{|c|}{ Success of Internet health information searching } \\
\hline Yes & 76 & 72 \\
\hline No & 28 & 27 \\
\hline \multicolumn{3}{|l|}{ Internet health information usefulness } \\
\hline Very useful & 63 & 60 \\
\hline Useful & 41 & 39 \\
\hline \multicolumn{3}{|l|}{ Not useful } \\
\hline \multicolumn{3}{|c|}{ Influence of Internet health information on personal health } \\
\hline a lot & 64 & 63.4 \\
\hline some how & 32 & 31.7 \\
\hline only a little & 5 & 5 \\
\hline \multicolumn{3}{|c|}{ Internet health information resulting in modifying health lifestyle } \\
\hline Yes & 76 & 72 \\
\hline No & 8 & 8 \\
\hline Maybe & 20 & 19 \\
\hline \multicolumn{3}{|c|}{ Internet health information affecting decision-making on health care } \\
\hline Yes & 59 & 56 \\
\hline No & 45 & 43 \\
\hline \multicolumn{3}{|c|}{ Internet health information leading to see a doctor or health provider } \\
\hline Yes & 67 & 64 \\
\hline No & 36 & 34 \\
\hline \multicolumn{3}{|l|}{ Internet health information Searching Skills } \\
\hline Key word searching & 77 & 73 \\
\hline Advanced searching techniques & 22 & 21 \\
\hline Following a thread & 5 & 5 \\
\hline Sources of Internet health information & & \\
\hline search engines & 92 & 89.3 \\
\hline health websites & 52 & 50.5 \\
\hline databases & 25 & 24.3 \\
\hline \multicolumn{3}{|c|}{ Challenges of searching or retrieving health information on-line } \\
\hline high cost of Internet bundles & 85 & 82.5 \\
\hline high cost of Internet devices & 26 & 25.2 \\
\hline slow and unreliable Internet connection & 69 & 67 \\
\hline poor searching skills & 24 & 23.3 \\
\hline unreliable power connection & 33 & 32 \\
\hline
\end{tabular}

According to Table 3, almost all respondents (97\%) were using the Internet for seeking health information. The frequency of on-line health information seeking was skewed, with the highest majority of the respondents (75\%) seeking 
on-line health information always, while $27 \%$ searched it once a while and $2 \%$ of the respondents never responded. Table 3 also revealed that Causes or symptoms of conditions or diseases (84.6) were the major information type that prompted respondents use of the Internet, closely followed by management or treatment of health conditions (76\%), nutrition or exercise information $(66.3 \%)$, and prescription or drug information (63.5\%). In addiction, as many as $76(72 \%)$ of the respondents agreed that they were always successful in finding the health information they searched for on-line. Only $(27 \%)$ admitted to not finding the health information they always searched for on-line. Cumulatively, the perception of Internet health information was considered useful by a high majority of the respondents (99\%).

Furthermore, when respondents were queried about the influence obtained Internet health information had on them, $96 \%$ of the respondents reported "a lot" to "some how" improvement in their personal health after using obtained Internet health information, only $5 \%$ felt that it had improved their personal health a little, while 4 failed to respond this query, also, $72 \%$ indicated that they had modified their lifestyle as a result of obtained Internet health information, and more than half $(56 \%)$ of the respondents admitted that health information they got from the Internet affected their decision-making concerning their health care while $43 \%$ of them felt that it never affected their health decision-making, and in addition, more than two thirds (64\%) of the respondents felt that obtained Internet health information had prompted them to see a doctor or health provider.

In terms of respondents' searching techniques for on-line health information, the results revealed that majority of the students $(73 \%)$ were using key word searching, only a little of $21 \%$ employed advanced searching techniques, while following a thread searching technique or snowballing searching recorded as low as 5\%. Moreover, the most common methods to finding health information on the Internet were using search engines $(89.3 \%)$, followed by health websites $(50.5 \%)$, and the least used source was databases $(24.3 \%)$. The major challenges encountered by respondents in their search for health information on-line were high cost of Internet bundles, slow and unreliable Internet connection, and unreliable power connection. The least challenge was poor searching skills (Table 3).

\section{Discussion}

The Internet has become the most popular source of information for many young people around the world due to the fact that it is widespread and the devices needed to access it have become common. Additionally, it contains significant amount of health information accessible with little effort. It therefore ensures the anonymity of the information seeker and thus reduces stigmatization associated with a patient accessing sensitive and embarrassing health related information. The study findings suggest that young people aged less 30 years were active users of the Internet, with almost $100 \%$ of the sample using it daily. This finding is a pointer to the fact that Internet utilization has become a norm among today's young people. This is similar to the findings of one European study that revealed that nearly $90 \%$ of European young people aged between 16-24 years were using the Internet daily [4]. Another study carried out in Ireland also found that majority of university students aged between 18 and 24 years were active users of the Internet [2]. The finding that significant majority of the students were experienced users of the Internet concurs with that of [19] where more than half $(59.1 \%)$ of students were very experienced in the use of the Internet, possibly due to the fact that this current generation grew up at a time when the Internet became widespread and available. This study also found that $91.3 \%$ of the participants owned smart phones indicating the widespread use and ownership of smart phones by today's young people. This finding corroborates with [5] that about $80 \%$ of young people in Ghana own a mobile phone or tablet with Internet connection. The finding that majority of the respondents (97\%) were using the Internet to seek Internet health information was not surprising considering that the Internet provides volumes of health information such as information on preventing and managing chronic diseases, causes or symptoms of common illness, sexual reproductive health, diagnosis and drug information, nutrition, fitness and exercise information, and many others, and since one study revealed that majority of the current generation of young people are known to have difficulties in accessing mainstream health services, the Internet becomes a convenient option for their health care needs. This finding is supported by similar works such as $[2,3,14,18-25]$. The current study further noted that causes or symptoms of diseases, management or treatment of conditions, nutrition and exercise, and drug information were the major health information determiners for using the Internet. This revelation is supported by [20] where majority of respondents used the Internet to look for symptoms of diseases and information on medications. It was also worthy of note and interesting to find that most of the participating students reported always being able to find the desired health information they searched for on the Internet probably because they might have high Internet searching skills and they maybe conversant with on-line health information sources. Access to health care information on-line was considered to be substantially useful as indicated by majority of the participants of the study. This is in congruence with the findings of several previous studies where retrieved on-line health information was always considered helpful and useful [18, 19, 21, 23]. Furthermore, findings of the current study revealed that $96 \%$ of the students felt that obtained Internet health information had improved the way they took care of their health "a lot" to "some how". This finding is consistent with the findings of [16] where $73.6 \%$ of university students reported "a lot to some how" improvement in their health after using Internet health information. Internet health information was found to be substantially influencing participants healthy lifestyles as well as their interactions with health care providers as indicated by significant majority of the students who admitted that they had modified their healthy lifestyle as a result of obtained Internet 
health information; most of the students confirmed that obtained Internet health information had affected their decision-making about their health and as much as $64 \%$ of the participants reported that obtained Internet health information stimulated a visit to a doctor or health provider. These findings are in agreement with prior studies such as [14, 16, 20]. In addiction, it was unsurprising that an estimated $73 \%$ of the students surveyed were using "key word searching" to fulfill their health-related information searching needs plausible due to the fact that this is what they are used to, and also may be, key word searching is a convenient form of conducting their searches. This finding is supported by similar works such as [3, $13,24,25]$. This study revealed a very important finding, that majority were not using electronic databases to retrieve health information. This important finding seems to be consistent with the findings of [21] where majority of respondents reportedly were not using databases such as Medline and Cochrane in fulfilling their Internet health information needs. The perceived barriers to retrieving on-line health information were high cost of Internet bundles, slow and unreliable Internet connection. This finding lends credence to other several findings $[16,21]$.

\section{Limitations}

This study has a number of limitations. The population of the study was a convenience sample of Narh-Bita college students. Therefore the findings may not be generalizable to other college populations. Respondents also self-reported their Internet use to obtain health information instead of observed behaviors. Future studies should build on these findings by exploring in-depth searching terms and strategies college students use to retrieve Internet health information.

\section{Conclusion and Recommendations}

The study findings revealed that the sampled students were active Internet users and majority of them were using it for seeking health information frequently. This results juxtaposes the efforts most institutions of higher learning have been making over the years to provide cheap and accessible Internet to students. Internet health information was found to be substantially influencing the participants interactions with their health care providers as well as affecting their medical decisions making thereby leading to modification of their healthy lifestyles. The participants demonstrated high Internet searching skills with the indication that majority of them always find the health information they sought on-line. However, there was a gap in advanced searching skills as only a few of the participants employed advanced searching techniques, yet this is key to locating relevant and useful Internet health information. In addiction, majority of the students perceived high cost of Internet bundles and slow and unreliable Internet connections as the major challenges they encountered in searching for health information on-line. Based on the findings, the following recommendations have been proposed:

1. Apart from the Internet being used for academic and leisure purposes, the Internet is now being heavily used for health care and health information purposes as showed by the findings of the study, therefore there is the need to promote e-health information as a viable option for meeting the health needs of many people especially young people. This means that e-health information should be easily accessible to all. This has the propensity to reduce the pressure and congestion at mainstream health centers in the long run since access to Internet health information has the potential to promote healthy adolescent lifestyles.

2. Institutions of higher learning should continue to provide cheap and affordable Internet access to all students as the benefits the Internet offers are endless. The problem of high cost of Internet bundles and slow and unreliable Internet connections should be addressed. The Government in collaboration with Telecommunication companies should be able to find a solution to these bottlenecks in order to obtain high speed and stable connections which are necessary for meaningful use of the Internet for both academic and health-related information purposes.

3. Attention needs to be paid to the students Internet searching skills to address any gaps in their knowledge and searching skills. This could take the form of organizing seminars and workshops on regular basis for the Narh-Bita college students to be abreast with the nitty-gritty of advanced searching techniques in order to able to obtain quality health information on-line.

\section{References}

[1] Perrin, A., \& Kumar, M. (2019). Internet activities, emerging technology impacts, technology adoption lifestyle. Accessed from https://www.pewresearch.org.

[2] Aine, H., \& John, S. (2019). University students on-line habits and their use of the Internet for health information. Computers Informatics Nursing, $30 \quad(8), \quad 402-408 . \quad$ Doi: 10.1097/NXN.ob013e3182510703.

[3] Montagni, I., Donisi, V., Tedeschi, F., Parizot, I., Motrico, E., \& Horgan, A. (2016). Internet use for mental health information and support among European universities students. The e-MentH Projec. Digital Health, 2, 1-16. Doi: $10177 / 2055207616653845$.

[4] Quarshie, H. Q., \& Ami-Narh, J. (2012). The growth and usage of Internet in Ghana. Journal of Emerging Trends in Computing and Information Sciences, 3 (9), 1302-1309. [Accessed 15 June, 2020] at http://www.cisjournal.org.

[5] Kankam, P. K., \& Nsibirwa, Z. (2019). Internet access and information retrieval competencies of high school students in Ghana. Library philosophy and Practice (e- journal). $\begin{array}{lllll}\text { [Accessed } & 20 & \text { May, } & 2020] & \text { at }\end{array}$ https://digitalcommons.unl.edu/libphilprac/2342.

[6] Akom, K., Asante, G., \& Adejei-Frimpong, B. (2016). An investigation into use of ICT tools in the TVET delivery: Evidence from Kumais Metropolis. International Journal of Computer Applications, 113 (7), 14-23. 
[7] Tao, D., LeRouge, C., Smith, K. J., \& De Leo, G. (2017). Defining information quality into health websites: A conceptual framework of health website information quality for educated young adults. JMIR Human Factors, 4 (4). [Accessed 17 July, 2020] at https://doi.org/10.2196/humanfactors.6455.

[8] Jadoon, N. A., Zahid, M. F., Mansoorulhaq, H., Ullah, S., Jadoon, B. A., Raza, A.... \& Hussain, M. (2011). Evaluation of Internet access and utilization by medical students in Lahore, Pakistan. BMC Medical Informatics Decision Making BMC Series, 11-37. DOI: 101186/1472- 6947.

[9] Burns, J. M., Webb, M., \& Durkin, L. A. (2010). Reach out central: A serious game designed to engage young men to improve mental health and well-being. Medical Journal of Australia, 192, 3270-330.

[10] Wang, L., Luo, J., Luo, J., Gao, W., \& Kong, J. (2012). The effect of Internet use on adolescents' lifestyle: A national survey. Computers in Human Behavior, 28 (6), 2007-2013. [Accessed 20 August, 2020] at https://doi.org/10.1016/j.chb.2012.04.007.

[11] Stellefson, M., Hanik, B., Chaney, D., Tennant, B., \& Chavarria, E. A. (2011). eHealth literacy among college students: A systematic review with implications for eHealth education. Journal of Medical Internet Research, 13 (4).

[12] Stellefson, M., Hanik, B., Chaney, D., \& Tennant, B. (2012). Analysis of eHealth search perspectives among female college students in the health professions using Qmethodology. Journal of Medical Internet Research, 14 (2). [Accessed 10 May, 2020] at https://doi.org/10.2196/Jmir.1969.

[13] O'Carroll, A. M., Westley, E. P., Dooley, J., \& Gordon, K. E. (2015). Information-seeking behaviors of medical students: A cross-sectional web-based survey. JMIR Medical Education, 1 (1).

[14] Albarrak, A. L., Mohammed, R., Zakaria, N., Alyousef, L. M., Almefqai, W. B., Alqahtani, H. A.,... \& Alsulaiman, A. A. (2016). The impact of obesity related websites on decisionmaking aong students in Saudi-Arabia. Saudi Pharmaceutical Journal, 24 (5), 605-610.

[15] Bakarman, M. A. (2017). Internet addition among senior medical students in King Adbulaziz University, prevalence and association with depression. Global Journal of Health Science, 9 (10), 60-68.
[16] Asibey, B. O., Agyemang, S., \& Dankwah, A. B. (2017). The Internet use for health information seeking among Ghanaian university students: A cross-sectional study. International Journal of Telemedicine and Applications, 20 (17), 1-9.

[17] Britt, R. K., Collins, W. B., Wilson, K., Linnersmeier, G., \& Englebert, A. M. (2017). eHealth literacy and health behaviors affecting modern college students. A pilot study of illness identified by the American College Health Association. Journal of Medical Internet Research, 101 (12).

[18] Zucco, R., Lavano, F., Anfosso, R., Bianco, A., Pilegi, C., \& Pavia, M. (2018). Internet and social media use for antibioticrelated information seeking: Findings from a survey among adult population in Italy. International J Journal of Medical Informatics, 111 (18), 131-139.

[19] Chung, J., Gassert, C. A., \& Kim, H. S. (2010). On-line health information use by participants in senior centres in Korea: Current status of Internet access and health information use by Korean older adults. International Journal of Older People Nursing, 6, 226-271. Doi: 10:1111/j.17483743.2010.00238.X.

[20] Alghamdi, E. S., Alqami, A. S., Bakarman, M., Mukhtar, A. M., \& Bakarman, M. A. (2019). Use of Internet health information among students in Jeddah, Saudi Arabia: A crosssectional study. Global Journal of Health Science, 1 (5), 51-58

[21] Onyi, T., \& Itopa, A. I. (2018). The utilization of Internet for health information in a Nigerian university. International Journal of Health Sciences and Research, 8 (3), 213-225.

[22] Adeyoyin, S. O., \& Oyewusi, F. O. (2015). A survey of the needs and utilization of health information among adults in Abeokuta, Ogun State, Nigeria. Library Philosophy and Practice (e-journal).

[23] Reinfeld-Kirkma, N., Kalchy, E., \& Roger, L. (2010). The relationship between self-reported heath status and the increasing likelihood of South Australians seeking Internet health information. Australian and New Zealand Journal of Public Health, 34 (4), 422-426.

[24] Yasin, B., \& Ozen, H. (2011). Gender differences in the use of Internet health information search. NISAN 11 (2), 229-240.

[25] Kam, J., Stanszus, D., Cheah, J. J., Heerasing, N., \& Tie, S. Y. (2010). The Internet as a health information source for university students. Australian Medical Student Journal, 1 (1), 24-26. 